\title{
Experiências de trabalhadores em ocupações urbanas em Uberlândia (MG)
}

\author{
Workers' experiences on urban occupations in Uberlândia (MG)
}

http://dx.doi.org/10.5007/2178-4582.2015v49n2p163

\author{
Denise Nunes De Sordi e Sérgio Paulo Morais \\ Universidade Federal de Uberlândia, Uberlândia/MG, Brasil
}

\begin{abstract}
Este artigo busca explicitar os modos como os trabalhadores, que ocuparam terras para a construção de moradias em Uberlândia (MG), entre os anos de 2000 a 2012, experimentaram condições e relações produtivas. Discutimos certas interpretações sobre a "luta pela cidade", a "luta pela reforma urbana", a "luta", as "melhores condições de vida" ou "única alternativa de vida" que buscam explicar a ação direta dos trabalhadores(as). A partir de dimensões estabelecidas entre a moradia, o trabalho e a luta, localizamos os sujeitos enquanto agentes nas formas como lidam com suas experiências e elaboram discursos sobre seu próprio entendimento acerca dos sentidos de economia, política, comunidade e justiça.
\end{abstract}

Palavras-chave: Ocupações urbanas - Trabalhadores-Agência.
This article seeks to highlight the ways in which workers, who have occupied land for housing construction in Uberlandia $(M G)$ between the years 2000-2012, experienced some conditions and productive relations. We discuss certain interpretations of the "struggle for the city", the "struggle for urban reform", the "struggle" itself for a "better life" or yet their "only alternative of life", in the attempt to explain the direct action of these workers. From dimensions established between housing, employment and struggle, we locate subjects as agents of the ways they handle their own experiences and how they elaborate discourses about their own understanding on economy, politics, community and justice.

Keywords: Urban occupations - Workers - Agency.

\section{Apresentação}

Instigados pelos numerosos movimentos de ocupação de áreas urbanas em Uberlândia (Minas Gerais) por famílias de trabalhadores entre os anos de 2000 a 2012, buscamos problematizar, a partir de indagações sobre tais processos de ocupação, os modos pelos quais as relações produtivas são construídas e vivenciadas pelos trabalhadores.

Com o objetivo de compreender os motivos pelos quais tais ocupações ocorrem, questionamos quem são os sujeitos que ocupam, por que ocupam, como é construído o espaço da ocupação e como as diferentes interpretações e projetos sociais que intencionam explicar ou justificar sua ação são articulados de modo a se reproduzirem enquanto voz uníssona das intenções e motivações dos trabalhadores. 
Nesse sentido, este artigo questiona quais são os significados constituídos e subjetivados por interpretações que definem a vida e as ações dos trabalhadores como "luta", "luta pela terra", "luta pela reforma urbana", "moradia digna", "melhores condições de vida", "única alternativa de vida" ou "condição de pobreza". Ao notar os trabalhadores que ocupam áreas urbanas, questionamos: o que ocorre quando ocupam? Como lidam com discursos e debates sobre sua ação? Como projetam aquele espaço de vivência, o bairro, para seu futuro e o de suas famílias? O que significa ser trabalhador e ocupar uma área urbana ociosa?

Ao buscar compreender tais dimensões e trajetórias de trabalhadores que ocupam áreas urbanas, foi fundamental problematizar o recorte temporal ligado a um marco institucional ou de políticas públicas direcionadas à moradia. Isso porque essa prática delimita as experiências dos trabalhadores, ao focar em um olhar macro relacionado a problemas como o déficit habitacional ou a falta de investimentos para moradias populares. Caso tal recorte fosse de fato empreendido como ponto articulador para compreender o processo de ocupações urbanas, despontariam inúmeras e importantes ações, influenciadas por diferentes movimentos sociais e lutas por direitos fundamentais e cidadania.

Destacam-se, neste aspecto, a inclusão da questão da moradia na Constituição da República Federativa do Brasil de 1988 (BRASIL, 1988), que instituiu um Estado Democrático e foi elaborada a partir da luta e empenho de diversos setores civis e demandas populares, como um dos Direitos Sociais'; a criação do Estatuto da Cidade (BRASIL, 2001); a Criação do Conselho Nacional de Desenvolvimento Urbano pela Medida Provisória n 2.220 (BRASIL, 2001b); a criação do Ministério das Cidades pela Lei n ${ }^{\circ} 10.683$ (BRASIL, 2003); a criação do Programa Minha Casa Minha Vida CMV pela Lei n 11.977 que também dispõe sobre a regularização fundiária de assentamentos localizados em áreas urbanas, dentre outras providências (BRASIL, 2009).

Numa perspectiva institucional de Uberlândia, destacam-se a Lei Municipal n²45/2000, Lei de Parcelamento e Zoneamento do Uso e Ocupação do Solo que, estabelece como "infração sujeita à multa, a comercialização de lotes originados de parcelamento irregular do solo urbano, em qualquer de suas modalidades sem a aprovação da administração pública" (FREITAS, 2005, p. 108). E, ainda, na trilha das demandas do Estatuto da Cidade, a instituição do Plano Local de Habitação Social (PLHIS) em Uberlândia em julho de 2009.

Não desconsideramos as importantes conquistas de lutas de atores sociais; pretendemos problematizar fatos e valores que intermediam e impulsionam 
determinadas ações e modos de vivenciar as relações produtivas. E . P. Thompson (2001, p.263) em Folclore, Antropologia e História Social, pontua que as transformações sociais e a consciência social são reveladas não tanto por relações estabelecidas entre diferentes campos da teoria, mas por meio de congruências (valores e expectativas que mediam trajetórias de vida mediante relações produtivas), de contradição (o conflito entre as lógicas de vivência, a ocupação dos sujeitos e como experiências de exploração forjam experiências vividas) e de mudança involuntária (mudanças que acabam por afetar as relações produtivas).

Recorrendo a diferentes perspectivas para interrogar e analisar os processos de ocupações urbanas, a investigação das narrativas dos trabalhadores, dos materiais produzidos por múltiplas interpretações, grupos e projetos sociais com falas sobre os trabalhadores apontou que as práticas, ou modos de vida e ação pelos trabalhadores, são organizados a partir de sua realidade social, das experiências e conflitos que vivenciam.

Além de dissertações, teses e artigos relacionados ao tema, as fontes elencadas compõem-se das matérias do jornal Correio de Uberlândia, segundo Corrêa (2014), o único jornal diário local, de 1999 a 2012; de vídeos documentários produzidos pelos movimentos estudantil da UFU, Comissão Pastoral da Terra (CPT) e de associações de moradores (AM), bem como narrativas produzidas a partir de entrevistas com moradores. Vale ressaltar que os vídeos documentários produzidos por tais organizações foram transcritos e que utilizamos as falas de trabalhadores de bairros como Joana D'Arc / São Francisco e Morumbi do setor Leste da cidade originados por ocupações, considerando o contexto no qual foram produzidos.

Argumentos recorrentes no jornal impresso e virtual Jornal Correio de Uberlândia e em materiais produzidos pelos movimentos sociais organizados citados foram problematizados, e dois vieses de debate em torno dos processos de ocupação foram evidenciados: o primeiro se baseia em interpretações e valores sobre as pessoas que ocupam essas áreas ociosas, identificados como "oportunistas", "pobres", "ignorantes", "folgados", "aproveitadores" etc.; o segundo tem como norte dimensões em torno da legitimidade da ocupação frente a práticas de especulação imobiliária e "exploração da burguesia", bem como o direito de permanência das famílias no local, a "luta por moradia", "a reforma urbana" e as inúmeras possibilidades e interesses de negociação, venda e desapropriação das áreas ocupadas por processos de alienação e espólio.

Falas sobre os trabalhadores estão organizadas em torno de embates e projetos políticos e sociais; e isso foi inquietante, pois, ao confrontarmos 
as entrevistas/narrativas e as evidências, questões semelhantes puderam ser evidenciadas entre os sujeitos ao atribuírem sentido às situações vividas, sobre os modos de apresentar motivos para ocupar, de reivindicar o acesso a determinados direitos - como à propriedade/moradia -, aos instrumentos de justiça, à vida, à segurança, ao conforto, à saúde, à educação, ao lazer, ao projetarem o futuro etc. Notar tais dimensões apontou para um movimento heterogêneo constituído por trabalhadores com diferentes experiências, trajetórias e objetivos, ainda que envoltos em dinâmicas semelhantes da comunidade.

A constituição de espaços de disputa e de debate em torno do tema da moradia extrapola a dimensão de obter uma casa para o morar e o pertencer. As atitudes e linguagens dos trabalhadores dialogam, a todo o momento, com os interesses e valores de grupos, projetos sociais e interesses que se projetam por valores e significados dominantes que são vividos pelos trabalhadores. O diálogo com Raymond Williams (2011) auxilia diante do conceito, pois:

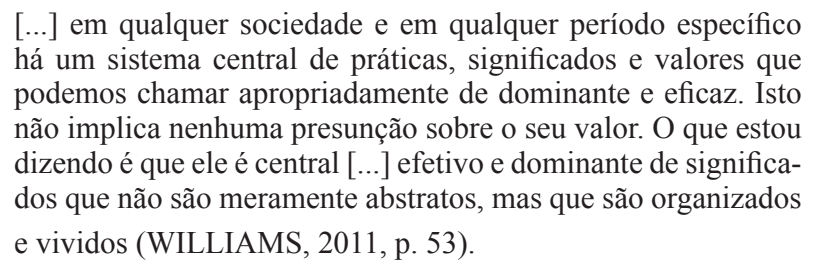

Somente com a definição dos sujeitos que ocupam áreas ociosas para moradia foi possível compreender as dinâmicas dos processos de ocupações urbanas, objeto desta investigação. Ao compreendermos os sujeitos em seu referencial histórico, as dimensões e relações vividas e estabelecidas entre os trabalhadores, puderam ser evidenciados os motivos e experiências que os impulsionam à ocupação.

Entre os anos de 2000-2012 é possível localizar uma complexa gama de ocupações em diferentes áreas de Uberlândia, localizadas em sua maioria nos setores Sul e Leste, reconhecidos por abrigar os bairros periféricos da cidade, a exemplo dos bairros Joana D'Arc / São Francisco. Ainda que tais ocupações não componham diretamente o lócus investigativo, é importante ressaltar que a análise de tais ações e narrativas de trabalhadores que formaram processos de ocupação e constituição de tais bairros levou-nos a atentar para dimensões e experiências entre trabalhadores que passaram por situações análogas, em diferentes momentos da ocupação da área do Glória.

A ocupação, reconhecida em Uberlândia como ocupação do "Glória", constituiu um norte de investigação sobre as ocupações urbanas. A área foi 
ocupada como desdobramento de outra ocupação, finalizada com o despejo de aproximadamente quatro mil famílias no ano de 2011, em local próximo à Central Estadual de Abastecimento (CEASA). Assim, o "Glória" foi ocupado no ano de 2012 por trabalhadores que haviam sido despejados da referida área, que saíram de outras ocupações ou, ainda, que eram locatários em bairros próximos à região. A área do Glória constitui-se na grande área pública da "Fazenda do Glória", propriedade da Universidade Federal de Uberlândia (UFU). Nesta área, então ociosa com 65,94 hectares e valor de alienação à UFU estimado em R\$30 milhões (BOENTE, 2012), hoje constitui o bairro "Elisson Prieto" com aproximadamente dez mil trabalhadores e trabalhadoras (DE SORDI, 2015)

\section{Sentidos e narrativas sobre o morar}

A noção de "Agência" legada por E. P. Thompson é remetida por Marcelo Badaró Mattos (2012, p.27) "à noção de que os homens são sujeitos de sua própria história, embora em condições que não escolhem”. Por este aspecto, interpretar as evidências observando os diálogos possíveis entre elas possibilitou que notássemos os caminhos de transformação de determinadas lógicas vigentes que ocorrem por meio de experiências vividas pelos trabalhadores, considerando-os enquanto agentes dessas transformações, e que sua ação impõe seus valores e experiências ao se projetarem socialmente diante de significados estabelecidos sobre o ocupar e o ser trabalhador.

Um dos motivos apresentados pelos trabalhadores para a ocupação de áreas urbanas ociosas é a construção de alternativas às relações de aluguel. Os trabalhadores apontam em suas falas a desvinculação do aluguel e das relações com o proprietário do imóvel alugado como fator que consideram prioritário ao considerarem aderir a uma ocupação por moradia. Retratam como recorrentes - tanto nas evidências de outras ocupações que construíram bairros como o Joana D'Arc/ São Francisco, como da ocupação da área do Glória - as tensões devido ao atraso no pagamento do aluguel, à situação desconfortável de moradia e ao alto valor das parcelas cobradas por imobiliárias e por particulares.

No período de constituição do bairro Joana D’Arc/São Francisco, analisamos a fala de alguns moradores que foram entrevistados para um vídeo documentário produzido pela Associação de Moradores do Bairro São Francisco/Joana D’Arc (AMBASF), pela Associação de Moradores do Bairro Joana D'Arc, pela Associação de Moradores do Bairro Morumbi, e pela Associação de Cidadania e Cultura Pérola Negra (ACCIPEN). O documentário, intitulado "Os valores culturais e o acesso à moradia: São Francisco de Assis e Joana D'Arc 3 anos. Um sonho de um povo. Uma história de luta” apresenta 
entrevistas com os ocupantes, como foi construído o processo de ocupação e constituição dos bairros no setor Leste de Uberlândia no ano de 2001 que, posteriormente, em 2012, tornaram-se bairros (COSTA, 2012). Quanto às motivações pautadas na problemática do aluguel, o morador, conhecido como Zé, argumenta sobre as difíceis condições vividas devido aos baixos salários:

\begin{abstract}
Nóis que ganha salário mínimo, a classe menos favorecida, não daria conta de pegar uma prestação num terreno de 280,00 real se há de convir que é difícil pra nós ganhar um salário e pagá, por exemplo, quem tem três filho, ou quatro, que seja, mesmo sendo um filho ainda já é difícil imagine com três. A maioria tava de aluguel, já num dando conta de pagá aluguel, tê que passá a noite escondido na oficina, que nem foi o meu caso, trabalhava na oficina, ajudava de mecânico auxiliar, e então num tinha como, outra saída a não ser entrar nessa invasão pra vê se conseguia um pedacinho, direito a morá né? $\mathrm{Na}$ face da terra, um direito digno de tê um memo tento pra mora no futuro né? Dexá pros filho, pelo meno né, então assim a nossa luta foi em prol disso aí, das dificuldade que nós vinha passando no dia-a-dia. Chegava não era o dono da casa, morava na frente, outro no fundo, não podia vir em casa porque não tinha o dinheiro de dá pra ele. Era difícil. Então, nós passô uma precisão muito séria que era um teto pra mora certo? (OS VALORES CULTURAIS..., 2012, p.4)
\end{abstract}

As dificuldades decorrentes da situação de locatário e a condição de classe menos favorecida apontam percepções sobre determinadas relações produtivas e os significados sobre a brusca experiência de ser privado do acesso à moradia devido ao baixo salário; o ser forçado a se esconder na oficina porque "chegava não era o dono da casa, morava na frente outro no fundo, não podia vir em casa porque não tinha o dinheiro de dá pra ele" compõe uma gama de questões e experiências vivenciadas pelos trabalhadores que vão definindo suas trajetórias e as possibilidades de transformação de sua condição material. Letícia, moradora do bairro Elisson Prieto, articula em sua narrativa, a questão da desproporcionalidade entre o salário e o valor médio dos aluguéis:

É o aluguel! O aluguel que aperta muito, né? Que aluguel hoje em dia cê num acha menos de quinhentos reais. [...] Aí cê vai trabalhar aí, eles quer te pagar setecentos reais: como cê paga com um salário desse? (DE SORDI, 2014)

Os trabalhadores problematizam as relações que vivenciam a partir de experiências, expectativas e reivindicações que se articulam mediante os modos pelos quais sentem, pensam, vivenciam e são. Quando diferentes interpretações e projetos sociais organizam suas ações, seja com a determinação dos tra- 
balhadores como "base" ou "pobres", suas ações políticas são ressignificadas e os sujeitos que ocupam terras urbanas para moradia passam a ser localizados como participantes dos movimentos de ocupação. Suas ações passam a conter outros sentidos, relacionados à especulação imobiliária, políticas públicas, baixos salários, ausência de educação forma e/ou consciência política.

Considerando que "os valores constituem um fundamento essencial da práxis" (KONDER, 2010, p.24), compreender como os trabalhadores enraízam tais valores em suas práticas apontou possibilidades para notar como modificam suas trajetórias de vida e as próprias dinâmicas do social.

As narrativas dos trabalhadores apontaram caminhos para compreender que a ida para a ocupação, enquanto alternativa real, ocorre antes no âmbito de suas próprias experiências que posteriormente são compartilhadas publica e politicamente. E. P. Thompson destaca que:

\footnotetext{
À medida que alguns atores principais da história - políticos, pensadores, empresários, generais - retiram-se da nossa atenção, um imenso elenco de suporte, que supúnhamos ser composto de simples figurantes, força sua entrada em cena (...). A vida "pública" emerge de dentro das densas determinações da vida "doméstica" (THOMPSON, 2001, p.235).
}

Por este aspecto, analisar as narrativas dos trabalhadores é também significar os modos pelos quais vivenciam determinadas relações e os sentidos que são elaborados a partir da experiência do viver e subjetivar tais relações. As ações de ocupações ocorrem relacionando-se aos fatos imediatos da falta de moradia e ao diálogo entre os trabalhadores sobre os significados do viver esse fato e a construção de possibilidades. E são motivadas pelos modos como as experiências de vida, os valores e o dia a dia, são vividos e negociados nos contextos históricos entre os sujeitos e a comunidade, em uma perspectiva de classe social, de seus interesses em comum.

Cristiano S. T., do bairro Elisson Prieto, narra os motivos pelos quais foi para a ocupação:

[...] moro aqui desde o primeiro dia, né? Da ocupação. Vim, porque num tinha nenhuma perspectiva de vida...tava num dando conta de pagá aluguel mais, tenho oito filho, e num teve outra saída a num [ser] tá aqui, correndo em busca de um teto que é a maior dificuldade [...] (DE SORDI, 2014)

As narrativas sobre as dificuldades, os motivos e as condições materiais de vida, semelhantes nas falas dos trabalhadores, aparecem contextualizadas 
na posição que ocupam mediante as relações sociais, culturais e produtivas que vivenciam. As narrativas informam sobre os sentidos e significados das injustiças de tais relações:

\begin{abstract}
Meu nome é Sônia, sou aqui de Uberlândia, há muito eu pagava aluguel o dinheiro que eu paguei aluguel é um dinheiro que não tem retorno. Foi isso que me cansou. E agora eu pretendo pagar o que é meu, estou aqui nessa luta, batalhando, junto da minha família que eles também tão aqui, tão batalhando, todos pra saí do aluguel. A gente quer pagar agora o que é da gente, e tamo animado! Tamo animado porque a gente tem gente do nosso lado, e a turma que tá aqui, são pessoas que precisam, pessoas que tem, é são trabalhadoras, que tem anos que tava né... precisando de uma casa pra morá, esperando í pra sua casa, né? Foi isso que me cansou. E agora eu pretendo pagar o que é meu (ACAMPAMENTO SEM TETO, 2013, p.3).
\end{abstract}

Sônia diz que não é apenas a privação da casa, do espaço da moradia: ela cansou dos modos como as relações estão estabelecidas; "as dificuldade que nós vinha passando no dia-a-dia" foram articuladas em uma percepção de outras possibilidades sobre como as relações podem ser instituídas de outra forma junto com "a turma que tá aqui."

Eliseu e sua esposa Juliana têm família em Uberlândia e já moraram em várias cidades mudaram-se para o bairro Elisson Prieto.

Eliseu: Eu moro aqui tem uns três meses.

Pesquisador(a): (...) e cê veio pra cá por quê?

Eliseu: Vim porque a gente [achou] melhor do que pagar aluguel. A gente tava pagando aluguel.

Pesquisador(a): (...) Como que cês resolveram vir pra cá?

Eliseu: Uai, meu pai comprou o terreno, aí a gente construiu e resolveu vim.

Pesquisador(a): E antes vocês moravam onde? Vocês já moravam juntos antes de vir pra cá? Já? Esse pequenininho [filho] é de vocês?

Juliana: É.

Eliseu: A gente morava ali no São Jorge [bairro vizinho a ocupação].

Juliana: Morava de aluguel.

Pesquisador(a): (...) quanto, mais ou menos, custava o aluguel ali? 
Eliseu: Trezentos e oitenta.

Pesquisador(a): E era, era uma casa como? Era grande? Era pequena?

Juliana: Só dois cômodo, né? Banheiro.

Eliseu: Banheiro, sala e quarto (DE SORDI, 2014).

A mesma condição foi relatada por outras moradoras que estão construindo o bairro Elisson Prieto, o caso de Cláudia que estava realizando sua mudança para o bairro no dia em em que concedeu entrevista:

Pesquisador(a): E aí, cê morava aonde antes?

Claudia: Eu morava no Tibery, aí eu vim pra cá.

Pesquisador(a): Você morava de aluguel de imobiliária ou particular?

Claudia: Não, particular.

Pesquisador(a): (...) mais ou menos quanto, você pagava [de aluguel]?

Claudia: Quatrocentos e oitenta!

Pesquisador(a): Quatrocentos e oitenta pra morar num lugar, como que era o lugar que cê morava?

Claudia: Não, lá era quatro cômodos, dois quartos, sala, cozinha e um quintalzinho.

Pesquisador(a): Ahã. E aí cê tá mudando hoje pra cá?

Claudia: Mudando, trazendo os trem hoje que tava terminando de coisa [refere-se ao término do acabamento interno da casa] aqui, né?

Pesquisador(a): E o que fez você vir pra cá?

Claudia: Uai, saí um pouco do aluguel, né? Porque tá tão difícil...Nossa! Dinheiro do aluguel difícil demais de pagar (Ibid.).

Ou de Josiane que, na data da entrevista, estava no bairro há quatro meses:

Pesquisador(a): Onde você morava antes de vir pra cá?

Josiane: Morava em casa de aluguel, lá na escola, lá em cima.

Pesquisador(a): Aqui no São Jorge. E por que que cê resolveu vir pra cá?

Josiane: Ah, porque ele tava ganhando pouco, né? O aluguel é muito caro, aí nós veio pra cá, o home ofereceu pra nós assim. 
Pesquisador(a): Quanto era o aluguel (...)?

Josiane: É duzentos e cinquenta! (...) Perguntou lá se nós queria vir pra cá, porque o povo tava querendo invadir [a casa] aqui, aí perguntou se nós queria vim, aí nós vim (Ibid.)

Os trabalhadores que ocupam terras ociosas para construir moradia são fazedores e agentes de suas próprias práticas na medida em que interpretam suas dificuldades, compreendem sua condição de vida e as relações de trabalho que vivenciam; não necessariamente precisam que estes sejam definidos de forma externa às suas experiências reais de vida.

\section{Significados sobre o ocupar}

O diálogo com artigos, dissertações e teses sobre o tema das ocupações em Uberlândia, e a análise das formas pelas quais os movimentos sociais organizados se posicionam enquanto representantes desses sujeitos, instigou questionamentos sobre como os trabalhadores vivenciam e compreendem os modos e relações produtivas. Tal problematização baseou-se no que E. P. Thompson define como a lógica histórica:

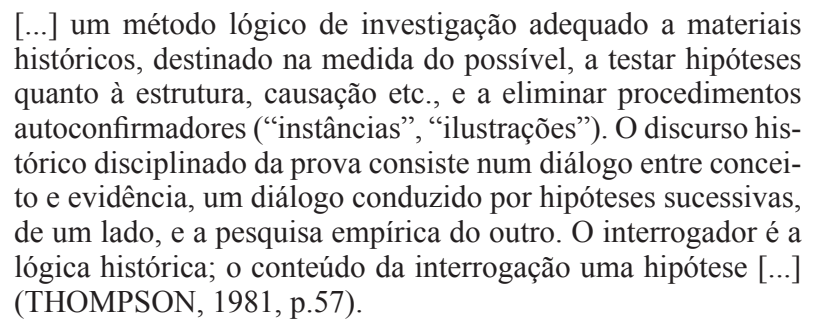

Tal lógica permitiu estabelecer o diálogo e o confronto entre as evidências e a análise crítica das narrativas produzidas a partir das entrevistas com os trabalhadores, na mesma proporção que ateve as indagações nos contornos das experiências vividas pelos sujeitos localizados nas ocupações urbanas por moradia, não permitindo a submissão das respostas às hipóteses. Desta forma, foi possível evidenciar os trabalhadores como sujeitos e agentes nas formas como lidam com suas experiências e elaboram discursos sobre seu próprio entendimento acerca dos sentidos do que é a economia, a política, a comunidade e justiça. Assim, emergiram os sentidos da construção de uma linguagem pelos trabalhadores que expressa determinado entendimento sobre uma condição comum de vida e de trabalho. 
Os diálogos que os movimentos organizados buscam instituir com a sociedade em geral, em síntese, buscam esclarecer os motivos pelos quais os trabalhadores ocupam terras, articulando-os em torno de questões ligadas, principalmente, à sua condição de pobreza e miséria, além da crítica aos programas habitacionais mais recentes, seja por sua ineficiência política ou morosidade em atender demandas habitacionais imediatas. Entretanto, quando os trabalhadores são interrogados sobre os motivos pelos quais estão ocupando e resistindo, articulam, em suas respostas, questões do cotidiano, como as dificuldades de manutenção familiar, o aluguel, dentre outras questões que impõem sua condição de trabalhadores, que expressam e articulam contradições e percepções sobre o lugar que ocupam nos meios de produção; e, com elas, as estratégias elaboradas para lidarem com situações adversas expressas nas interpretações sobre como estão construindo possibilidades e vivenciando-as.

Há uma relação de classe estabelecida que pode ser notada em tais modos de articular alternativas às propostas e projetos vigentes que buscam atender determinadas demandas que partem da identificação dos trabalhadores como indivíduos que se encaixam em "perfis", "situações" e "atitudes". A alternativa de ocupar terras urbanas por moradia encontra respaldo nas trajetórias dos indivíduos, na medida em que confere realidade às expectativas de outras possibilidades que, até então, estavam além das apresentadas por sua condição material, que pode ser definida por questões de exploração no trabalho, problemas familiares, financiamentos, aluguéis, empréstimos, ausência de apoio material e afetivo, intervenção pública efetiva etc.

Ao construírem tais alternativas, os trabalhadores forjam ações com base nas suas experiências em comum, em um sentido de identificação, pois, passam a partilhar de um objetivo final comunitário que é a obtenção do lote para a construção da moradia. No processo de ocupação, o direcionamento das trajetórias de resistência por moradia representa momentos de incerteza, de impacto e de obstinação na defesa e conquista desse objetivo. Puderam ser evidenciadas as ações em comum entre os trabalhadores, bem como a demarcação, ou legitimação, de posicionamentos referenciados em elaborações morais sobre seus direitos, a dignidade ou a cidadania, localizadas, por sua vez, a partir da posição que ocupam diante determinadas relações de produção.

Entretanto, isso não significa elaborar que os trabalhadores constituam um movimento homogêneo, mas que se identificam a partir de suas experiências, práticas e objetivos. Tais identificações também são definidoras das situações experimentadas no processo de lutas por moradia, de suas estratégias de ação, de negociação enfim, diversas formas de oposição e enfrentamento aos interesses de determinados agentes dominantes - proprietários, 
representantes do poder público, pesquisadores, lideranças dos movimentos, padres, pastores etc.

Nesse sentido, as estratégias notadas nas narrativas sobre os processos de ocupação pela moradia em Uberlândia apontaram ações de solidariedade, de resistência, de silêncio sobre o vizinho, de atitudes de resguardo da comunidade, do compartilhar alimentos, dos conflitos, do vender fiado, dentre outros, que forjam ações de classe naquele contexto ao ser interpretada ou

(...) determinada, em grande medida, pelas relações de produção
em que os homens nasceram - ou entraram involuntariamente.
A consciência de classe é a forma como essas experiências são
tratadas em termos culturais: encarnadas em tradições, sistemas
de valores, ideias e formas institucionais [...] (THOMPSON,
1987, p. 10)

Alguns temas são mais frequentes nas narrativas dos trabalhadores e constituem formas de abordagem de suas experiências, guiando abordagens sobre os sentidos das suas trajetórias e ações ao buscarmos suas referências e discussões históricas. Ao definirmos tais referências e discussões, é possível evidenciar a organização de uma linguagem comum que os trabalhadores utilizam para se referirem às suas próprias interpretações sobre questões políticas. Ou seja, expressam tais questões com referência nos modos como as vivenciaram, ao mesmo tempo em que as localizam a partir de seu lugar social e, principalmente, o que anseiam como resultado de sua ação, que é referenciada nos sentidos expressos, ou intermediados, por essa linguagem.

Ao considerarmos que os indivíduos não são fracionados ou polarizados entre sua condição e perspectivas de vida, é possível notar como projetam modelos de vivência em atividades diversas, nas perspectivas para a construção de suas casas, no emprego, na saúde, na família e na alimentação. Garcia pontua que:

\footnotetext{
A heterogeneidade dos discursos culturais expressa a diversidade de pontos de vista que caracteriza uma sociedade transpassada por desigualdades. Para seus agentes, a prática discursiva é o instrumento no qual constroem e expressam seus interesses. (...) Se os sistemas simbólicos são efetivamente produtos sociais, comportam simultaneamente uma dimensão positiva e dinâmica; eles têm a potencialidade de, articulados pelos homens, intervir na ordenação do mundo alterando significados. Por essa via a ordem social deixa de ser vista como um contínuo totalmente estruturado; comporta brechas e fissuras, espaços potenciais de contestação. Heterogeneidade e diversidade caracterizam um discurso que descreve o social como fragmentação (GARCIA, 1996, p. 164-165).
} 
Em determinados contextos históricos, a formação de processos de ocupação urbana por trabalhadores os situa como agentes dos meios pelos quais poderão ou não atingir suas expectativas e objetivos e, ao empenharem sua experiência naquilo que constroem, recolocam a dimensão humana nos processos de ocupação e resistência. Já que esta dimensão é, em geral, engolida por forças organizativas da administração municipal, da polícia militar ou pela privação ao acesso a bens e serviços. Para os que pressupõem a presença da dimensão hegemônica dessas forças, já nos foi dito pelos trabalhadores que "hoje somos nós, amanhã depois vai se eles.” (ACAMPAMENTO SEM TETO..., 2013, p.2).

No entanto, vale ressaltar, que são agentes em contextos históricos específicos, justamente pela razão de que não é por serem ativos em determinados momentos que possuem intenção, forças ou meios para remodelar ou transformar integralmente a organização das relações sociais. Seus objetivos e interesses compõem determinados processos de luta e lidam com a regulação de suas ações por tipos de intervenções representadas, por exemplo, na administração pública, nas estratégias propostas pelos movimentos sociais, pela influência de entidades religiosas e de Organizações não Governamentais. Tais entidades, organizações e movimentos intervêm nos modos pelos quais questões ligadas ao cotidiano dos trabalhadores serão encaminhadas nos aspectos da moradia, da alimentação, do sustento etc. Há termos estabelecidos mediante certas relações sociais sobre como essas entidades trilharão os caminhos para que os objetivos e expectativas dos trabalhadores sejam atingidos.

A questão do (des)emprego e das relações produtivas injustas é frequente nas narrativas como elemento da condição para ocupar. Claudia explica que viu uma possibilidade na ocupação devido às ua situação de desemprego:

Claudia: Bom, eu moro aqui trinta e cinco anos!

Pesquisador(a): Aqui em Uberlândia?

Claudia: É. É, agora eu tô desempregada né? Então, tive essa oportunidade eu vim pra cá.

Pesquisador(a): E você trabalhava com o quê antes?

Claudia: Auxiliar de cozinha. (...) Aqui na cidade (DE SORDI, 2014).

As mulheres encontram maiores dificuldades por não terem o apoio de creches:

Letícia: Ahã. Na verdade assim, ele saiu, ele saiu do emprego e eu consegui o Carrefour, então ele ficou só [...] Com os bico e os serviço aqui, aí ele arrumou na pizzaria e eles não conseguiram, não quiseram mudar meu horário, sabe? Aí eu tive que sair porque a pizzaria é de noite, não tinha com quem deixar eles [os filhos] de noite, eles me passaram pra de manhã 
e eu tive que sair, agora que eu tô, ajeitando pra conseguir a escolinha dela aqui pra procurar de novo o horário comercial.

Pesquisador(a): E agora você tá pensando em procurar [emprego] aonde mais ou menos?

Letícia: Ai, nem sei, nem sei. Pro mercado, as área administrativa num tá, parece que num tá pegando, queria mais, assim, escritório, assim, por causa de ser, de segunda a sexta, né? Que esses outros de uma folga só na semana, quando cê tem criança é difícil, num sobra muito tempo, e eles tá pra escola, de noite cê tá em casa, cê tá trabalhando, aí fim de semana cê tem um dia só, né? Eu falo o dia que cê tem, eles tá pra escola, então é mais puxado, mas num dé jeito, tem que ser (Ibid.)

É relevante apontarmos que são as mulheres, justamente por ficarem impossibilitadas, muitas vezes, de manter seus empregos para cuidar dos filhos e da casa, que "garantem" o barraco ou o lote, marcando presença, resistência e interesse, nos processos de ocupação. Identificamos como recorrentes, na fala dos trabalhadores, argumentos relativos ao bairro que construíram, de que "aqui é todo mundo trabalhador", ou de que "é um bairro como qualquer outro". Ao ser perguntada sobre ações de caridade de agentes externos no bairro, Letícia apresenta esses argumentos:

Leticia: (...) aqui é um bairro como outro qualquer, quem mora aqui, todo mundo sai pra trabalhar, leva os meninos pra escola, volta, é, (...) Quer dar brinde pros menino, quer dar cesta básica, é bem-vindo, pode dar. Pode me dar, né Estér?! [Com a filha que estava no colo] E, balinha... agora, de curso assim, eu já vi assim várias vezes de roupa, de deixarem roupa aqui, mas assim...

Pesquisador(a): Aqui na sede?

Letícia: Até aqui atrás tinha umas roupas que sobrou aqui... sapato.

[As roupas estavam em sacolas plásticas no chão, atrás das muretas em que estávamos sentadas] (...) Mas eu nunca vim, olhar nem nada, então eu num sei te falar nem nada (DE SORDI, 2014).

Em suas narrativas, os sujeitos articulam modos de combater determinadas interpretações a ações que possam deslegitimar seus modos de vida, ou sua ação direta que, por sua vez, desestabiliza e questiona ordenamentos sociais de relações produtivas até então vigentes, como pagar o aluguel, ficar endividado, ter que morar com a família, pagar aluguel por condições precárias, aceitar 
doações de roupas etc. Fatos que, de certa forma, desconsideram sua condição de sujeitos e pessoas com autonomia, vontades e potencialidades.

Assim, ao notarem como são interpretados, por determinado viés dominante, em outras regiões da cidade consideradas "regulares", articulam discursos nos quais interpretam suas experiências, para marcar sua presença nesse terreno de conflitos permeado pelas relações de forças políticas e sociais que centralizam a condição de pobreza como inerência em determinados momentos, exercendo pressão sobre os trabalhadores e retirando todos os significados articulados entre o agir, o ocupar e resistir para conquistarem sua moradia e projetarem diferentes possibilidades de vida que contrariam valores estabelecidos para sua condição de trabalhador.

\section{Considerações finais}

De forma subjetiva, os modos de morar, trabalhar e viver, de se inscrever no espaço urbano e constituir a memória praticados por grupos dominantes em Uberlândia podem ser questionados quando os trabalhadores expressam e colocam em movimento os sentidos e as formas como compreendem suas condições de vida.

Investigar e refletir sobre quem são esses trabalhadores que ocupam terras por moradia, os motivos pelos quais ocupam, suas expectativas, as experiências que conferem sentido à sua ação e as linguagens e práticas que instituem, é também compreender como se organizam as relações sociais e econômicas, as problemáticas destas relações e o estabelecimento de dinâmicas, que são diretas e recíprocas, entre proprietários e ocupantes, poder público e movimentos sociais organizados, mídia privada e opinião pública.

Ao refletirmos sobre a relação entre "a gentry" e os "trabalhadores pobres" proposta por E. P. Thompson (1998) - que sugere três características da ação popular (a tradição anônima, o contrateatro e a ação rápida e fugaz), salvo o contexto da obra do autor - é possível vislumbrar a importância e os significados que se constituem com a ação de trabalhadores em torno de um objetivo: o de uma reivindicação. Para o autor, considerando que esse objetivo expressa relações de subordinação e insubordinação constituídas por modos conscientes e por vias das práticas culturais, de viver, de trabalhar e de lutar:

[...] É possível mencionar outras características, mas essas três - a tradição anônima, o contrateatro e a ação direta rápida e fugaz - parecem ter importância. Todas dirigem a atenção para o contexto unitário da relação de classe. Num certo sentido, os governantes e a multidão precisavam uns dos outros, vigiavam-se mutuamente, representavam o teatro e o contrate- 
atro um no auditório do outro, moderavam o comportamento político uns dos outros. Intolerantes com a insubordinação do trabalho livre, ainda assim os governantes da Inglaterra demonstravam, na prática, um grau surpreendente de tolerância com a turbulência da multidão. Há aqui alguma "reciprocidade" estrutural profundamente arraigada? Considero essa noção de reciprocidade gentry-multidão, de "equilíbrio paternalismo-deferência", em que os dois lados da equação eram, em certa medida, prisioneiros um do outro, mais proveitosa do que as noções de "sociedade de uma só classe", de consenso ou de uma pluralidade de classes e interesses. O que deve nos interessar é a polarização de interesses antagônicos e a dialética correspondente da cultura (THOMPSOM, 1998, p. 68).

Os sentidos sobre viveres que os sujeitos narram expressam como compreendem as elaborações feitas sobre suas práticas, hábitos e condição de vida. Nilda, moradora na ocupação do Glória/Elisson Prieto, ressalta que não é só o bairro, o lugar, são os moradores, as relações e os modos como se inscrevem ou direcionam suas possibilidades:

Nilda: (...) Eles só mostra o lado bom, o Rio de Janeiro é a cidade mais linda do mundo, num tem problema. Porque muitos veio passear de fora e num conhecer? Quando chega lá eles assusta! A mesma coisa aqui, né? Só que aqui tá, tá aí a diferença! Porque aqui muita gente honesta e muita gente trabalhador, gente que tem religião, gente que talvez tem tanto conhecimento que a gente nem imagina, talvez aqui tem tanta gente que possa se aproveitado, né? E tão sendo excluído, quase que excluído. [...] Porque aqui é considerado como uma favela! Porque é considerado como uma invasão, como uma as pessoas que, sei lá, um mendigo! Aqui é considerado assim! E num é isso! Todo mundo quer?! Queremos! E num queremos de graça, e num... queremos pagar, mas nós queremos o nosso direito e nós num queremo... nossa casa (...).(DE SORDI, 2014).

Chamam-nos a atenção as características elencadas por ela para falar do lado bom do bairro: "muita gente honesta e muita gente trabalhador, gente que tem religião, gente que talvez tem tanto conhecimento que a gente nem imagina. Ao deixar de pagar o aluguel a condição da ocupação de terras por moradia se configura como uma possibilidade de fazer outras coisas que até então não eram possíveis:

[...] nessa moradia de dez meses sem pagá aluguel, dez meses sem... sem... comendo pão e tomando café de manhã, dez meses até... assa a carninha no final de semana, porque na hora o dinheirinho que pagava o aluguel sobrou... Então, assim (...) (DE SORDI, 2012, p.8). 
Ao atentarmos para tais possibilidades, apontadas nas narrativas dos trabalhadores, evidenciam-se diversas formas de regular tal condição. Há a falta de serviços básicos, de alimentos, de roupas, de dinheiro, etc., mas o bairro e a vida estão sendo construídos e essas novas possibilidades permitem conquistar outra condição de vida para o presente e para o futuro que não estava disponível até então:

Nilda: O dinheiro do aluguel, as pessoas, hoje, eu vejo gente falar pra mim aqui, que já tem o que num tinha aqui, hoje, num tá pagando um aluguel, nem uma água, nem uma luz, tão dando conta de comprar uma bicicleta pra andar, tão dando conta de comprar um guarda roupa que num tinha, um fogão novo ou uma televisão, um móvel pra casa que eu acho que é digno! Todo mundo tem que te! E antes muita gente num tinha, e agora tem, por quê? Porque tá sobrando, um pouquinho da luz, do aluguel e da água, e o dinheiro do aluguel tá investindo na casa, porque cê vê, o rapaz do material de construção aqui, já sabe! No começo do mês todo mundo recebe, vai dando que é uma beleza, aí do dia quinze pra frente, pára as venda! Porque num tem mais dinheiro, né?! Vai esperar receber novamente, pra começar a comprar, então eu acho que, tá sendo uma ajuda muito boa! Porque quem tá aqui é porque tá recebendo minha filha se você vê a poeira aqui quando, hoje tá bom! Choveu! Quando é poeira mesmo, cê entra aqui cê fala "não, num tem condição desse povo morar aqui" porque que enfrenta? Porque... pra poder conseguir a sua moradia! É o futuro dos filho da gente! Dos neto, né? (DE SORDI, 2014).

Abordar os processos de ocupações urbanas, principalmente, a partir das perspectivas e experiências das pessoas que ocupam, permite apreender como as pessoas se relacionam com sua própria história e seu contexto, como a compartilham, como influenciam e como são influenciadas por sua condição e valores ao escolherem e construírem alternativas de vida frente às possibilidades e condições reais. Tais dimensões emergem dos sentidos e significados sobre o morar, o trabalhar e o viver, ainda que estes estejam articulados em certas ordenações cotidianas, determinadas, até então, pelas relações produtivas vigentes.

\section{Referências}

ABIU - Uberlândia, MG. Associação de Bairros Irregulares de Uberlândia. Os valores culturais e o acesso à moradia. Canal ABIU - Duração: 00:23:49. 22 set. de 2012. Disponível em: $<$ http://www.youtube.com/watch?v=pG0aYE1pAFc $>$. Acesso em 14 out. de 2013.

ACAMPAMENTO SEM TETO - Elisson Prieto Uberlândia MG. Canal da AFES MG - Associação Franciscana de Ecologia e Solidariedade. Duração 00:11:06. Publicado em 29. abr. 
de 2013. Disponível em: <http://www.youtube.com/watch?v=f_GxDdTzaT0>. Acesso em: 04 nov. 2013.

BRASIL (Presidência da República). Constituição da República Federativa do Brasil de 1988. Brasília, DF, 5 de outubro de 1988. Disponível em: < http://www.planalto.gov.br/ccivil 03/constituicao/Constituicao.htm> . Acesso em: 13 jul. 2014.

Lei ${ }^{\circ}$ 10.257/01. Estatuto da Cidade. Regulamenta os arts. 182 e 183 da Constituição Federal, estabelece diretrizes gerais da política urbana e dá outras providências. Brasília, 10 de julho de 2001a. Disponível em: <http://www.planalto.gov.br/ccivil_03/leis/LEIS_2001/ L10257.htm>. Acesso em: 16 nov. 2014

Medida Provisória n 2.220, de 4 de setembro de 2001. Dispõe sobre a concessão de uso especial de que trata o $\S 1$ o do art. 183 da Constituição, cria o Conselho Nacional de Desenvolvimento Urbano - CNDU e dá outras providências Brasília, 4 de setembro de 2001b. Disponível em: < http://www.planalto.gov.br/ccivil 03/mpv/2220.htm $>$. Acesso em: 13 jul. 2014.

Lei $\mathbf{n}^{\circ}$ 10.683, de 28 de maio de 2003. Dispõe sobre a organização da Presidência da República e dos Ministérios, e dá outras providências. Brasília, 28 de maio de 2003. Disponível em: < http://www.planalto.gov.br/ccivil 03/leis/2003/L10.683compilado.htm> . Acesso em: 13 jul. 2014.

BRASIL (Caixa Econômica Federal). Minha Casa, Minha Vida. Governo Federal do Brasil, Brasília, DF. 2012. 46 p.

BOENTE, Fernando. UFU e governo federal negociam regularização de área invadida. Correio de Uberlândia, 17 out. de 2012. Disponível em: <http://www.correiodeuberlandia.com. br/cidade-e-regiao/ufu-e-governo-federal-negociam-regularizacao-de-area-invadida/ $>$ Acesso em: 20 jan. 2013

CAIXA ECONÔMICA FEDERAL. Demanda Habitacional no Brasil. Brasília: CAIXA, 2011. 170 p.

COMO PRODUZIR MORADIA BEM LOCALIZADA COM RECURSOS DO PROGRAMA MINHA CASA MINHA VIDA? Implementando os instrumentos do Estatuto da Cidade / Organização de Raquel Rolnik, textos de Raphael Bischof, Danielle Kintowitx e Joyce Reis. Brasília: Ministério das Cidades, 2010. 132 p. Disponível em: <http://polis.org.br/wp-content/uploads/ como produzir_moradia.pdf $>$ Acesso em: 10 ago. 2015.

CORRÊA, Gleide. Sobre o Correio. História. Correio de Uberlândia, s/d. Disponível em: $<\underline{\text { http:// }}$ www.correiodeuberlandia.com.br/sobre-o-correio-de-uberlandia/> Acesso em: 14 jul. 2014.

COSTA, Danielle. Uberlândia ganha três novos bairros. Correio de Uberlândia. Cidade e Região. 17 março de 2011. Disponível em: $<\underline{\text { http://www.correiodeuberlandia.com.br/cidade-e-re- }}$ giao/uberlandia-ganha-tres-novos-bairros $>$. Acesso em 10 dez. 2012.

DE SORDI, Denise Nunes. Reunião MSTB e entidades estudantis da UFU. Centro de Convivência do Campus Santa Mônica, Universidade Federal de Uberlândia (MG). 10 out. de 2012. Transcrição de entrevista. Acervo de Pesquisa. 24 p.

Moradia, Trabalho e Luta: experiências práticas e perspectivas sobre ocupações de

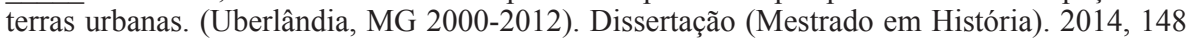


f. Programa de Pós-graduação em História, Universidade Federal de Uberlândia, Uberlândia, 2014.

FREITAS, Cláudia Maria de. Regularização da ocupação urbana em Uberlândia: loteamento São Francisco/ Joana D'Arc - uma contribuição. 2005, 137 f. Dissertação (Mestrado em Geografia) Instituto de Geografia, Universidade Federal de Uberlândia. Uberlândia, Uberlândia, 2005.

GARCIA, Sylvia Gemignani. Cultura, dominação e sujeitos sociais. Tempo Social Rev. Sociol. USP, S. Paulo, V. 8, n. 2, p. 159-176, out. de 1996. Disponível em: $<$ http://www.scielo.br/pdf/ ts/v8n2/0103-2070-ts-08-02-0159.pdf> Acesso em: 10 ago. 2015.

KONDER, L. Em torno de Marx. São Paulo: Boitempo, 2010. 133p.

MATTOS, Marcelo Badaró. E.P.Thompson e a tradição de crítica ativa do materialismo histórico. Rio de Janeiro: Editora UFRJ, 2012. 288p.

PREFEITURA MUNICIPAL DE UBERLÂNDIA. Banco de Dados Integrados. vol. 1. Prefeitura Municipal de Uberlândia. Secretaria Municipal de Planejamento Urbano e Meio Ambiente, 2007. Disponível em: <http://www.uberlandia.mg.gov.br/uploads/cms b arquivos/1450. pdf $>$. Acesso em 12 ago. 2015.

. Plano Local de Habitação de Interesse Social de Uberlândia - Diagnóstico Estratégico de Habitação de Interesse Social. Uberlândia, novembro de 2009. Disponível em: $<$ http://www. uberlandia.mg.gov.br/uploads/cms b_arquivos/6342.pdf $>$ Acesso em: 10 ago. 2015.

PRIETO, Elisson Cesar. Os desafios institucionais e municipais para implantação de uma cidade universitária: o Campus Glória da Universidade Federal de Uberlândia. 2005. 268 f. Dissertação (Mestrado em Geografia). Instituto de Geografia, Universidade Federal de Uberlândia. Uberlândia, Uberlândia, 2005.

THOMPSON, Edward Palmer. A miséria da teoria ou um planetário de erros - uma crítica ao pensamento de Althusser. Rio de Janeiro: Zahar Editores. 1981. 231 p.

.A Formação da Classe Operária Inglesa. A árvore da liberdade. vol. 1. Trad. Denise Bottmann, Paz e Terra, RJ, 1987. 204 p.

.Costumes em Comum. São Paulo: Companhia das Letras, 1998. . 493 p.

. As peculiaridades dos ingleses e outros artigos. Campinas, SP: Editora da

Unicamp, 2001. 286 p.

WILLIAMS, Raymond. Cultura e Materialismo. Trad. André Glaser. São Paulo: Editora Unesp, 2011. 420 p.

Submissão em: 10/02/2015

Aceite em: 01/06/2015 
Denise Nunes De Sordi é doutoranda em História Social pelo Programa de Pós-Graduação em História Social da Universidade Federal de Uberlândia. Endereço para correspondência: UFU / Programa de Pós-Graduação em História. Rua João Naves de Ávila, 2121 - Bloco 1H, sala 1H50. Santa Mônica. Uberlândia/ MG, Brasil. 38408-100 E-mail: denisends@gmail.com

Sérgio Paulo Morais doutor em História (PUC-SP), professor do curso de Graduação e Pós-graduação em História e do curso de pós-graduação em Educação, ambos da Universidade Federal de Uberlândia. E-mail: moraissp@yahoo.com.br 